\title{
Videocirurgia aplicada ao aparelho geniturinário em pequenos animais
}

\author{
Marco Augusto Machado Silva
}

Professor Adjunto da Faculdade de Agronomia e Medicina Veterinária, Universidade de Passo Fundo, RS (FAMV/UPF).

ISSUE DOI: $10.3738 / 1982.2278 .1147$

A exigência por alternativas de tratamentos e procedimentos cirúrgicos menos traumáticos por parte dos proprietários de pets a seus animais é crescente no mercado brasileiro. Nesse contexto, a cirurgia endoscópica, também denominada videocirurgia, cirurgia vídeo-assistida ou laparoscópica assume papel importante por proporcionar a realização de intervenções cirúrgicas de graus de complexidade variados por pequenos orifícios de acessos cirúrgicos abdominais, denominados portais, da ordem de dois a $20 \mathrm{~mm}$ de extensão. Como resultado, há menor trauma tecidual e, consequentemente, melhores resultados estéticos, menor dor pós-operatória e tempo de convalescência, risco reduzido de complicações tais como hemorragias, hérnias incisionais e outras complicações de ferida cirúrgica, gerando satisfação por parte dos proprietários. A principal aplicação da videocirurgia no trato reprodutor em pequenos animais é a castração por ovário-histerectomia ou ovariectomia, além da orquiectomia em machos criptorquidas. Nesses casos, o procedimento pode ser realizado empregando-se um, dois ou três portais, sendo a hemostasia profilática dos vasos sanguíneos alcançada mediante uso de diatermia monopolar, coagulação bipolar ou ultrassônica, além das ligaduras extracorpóreas (endoligaduras) ou intracorpórea utilizando-se porta-agulhas laparoscópicos emprego de energia ultrassônica. Outra importante aplicação da videocirurgia do trato reprodutor em machos é a cirurgia prostática, tanto para obtenção de biópsias vídeo-assistidas, quanto para a realização de drenagem e omentopexia de cistos e prostatectomia, em casos de neoplasia prostática maligna. Cita-se ainda outros recursos tais como realização de inseminação artificial vídeo-assistida e biópsias e ressecções de massas suspeitas de neoplasias por vaginoscopia. No âmbito da cirurgia urológica, todos os procedimentos cirúrgicos do trato urinário cujo acesso se dá pela cavidade abdominal podem ser realizados por laparoscopia eu acesso vídeo-assistido, dependendo do nível de treinamento da equipe cirúrgica e do equipamento e instrumental disponível. Dentre as possíveis cirurgias urológicas por vídeo, citam-se: biópsia renal; nefrectomia radical, para neoplasias ou parasitismo por Dyoctophima renale; nefrotomia, pielotomia e ureterotomia para remoção de urólitos; reimplante ureteral para rupturas ou ectopia ureteral congênita; derivações urinárias vídeoassistidas, como cistostomia e uretrostomia pré-púbica; cistotomia vídeo-assistida para remoção de pólipos de mucosa vesical ou cálculos vesicais. Além desses procedimentos, pode-se realizar a 
uretrocistoscopia diagnóstica, com possibilidade da realização de biópsias e inserção de sonda ureteral por cistoscopia. As principais limitações ou dificuldades da videocirurgia são inerentes ao treinamento ou curva de aprendizado por parte da equipe cirúrgica e ao custo de implementação do serviço de videocirurgia. Todavia, trabalhos científicos recentes demonstram que, para determinadas cirurgias, cerca de 20 a 40 procedimentos possibilitam que a curva de aprendizado seja alcançada, além de treinamentos em simuladores antes da realização de procedimentos in vivo. Ademais, os custos de implementação vêm decrescendo, à medida em que novas tecnologias são disponibilizadas no mercado, possibilitando a agregação de valores à clínica ou hospital veterinário que investe na obtenção do sistema de vídeo no aspecto do marketing e nas possibilidades de realização de exames e de cirurgias.

Palavras-chave: técnicas cirúrgicas, laparoscopia, endoscopia diagnóstica, urologia, obstetrícia, animais de companhia. 